\title{
An Impact of Biofield Treatment on Spectroscopic Characterization of Pharmaceutical Compounds
}

\author{
Mahendra Kumar Trivedi ${ }^{1}$, Shrikant Patil ${ }^{1}$, Harish Shettigar ${ }^{1}$, Ragini Singh ${ }^{2}$ and Snehasis Jana ${ }^{*}$ \\ ${ }^{1}$ Trivedi Global Inc., 10624 S Eastern Avenue Suite A-969, Henderson, NV 89052, USA \\ ${ }^{2}$ Trivedi Science Research Laboratory Pvt. Ltd., Hall-A, Chinar Mega Mall, Chinar Fortune City, Hoshangabad Rd., Bhopal- 462026, Madhya Pradesh, India
}

\begin{abstract}
The stability of any pharmaceutical compound is most desired quality that determines its shelf life and effectiveness. The stability can be correlated to structural and bonding properties of compound and any variation arise in these properties can be easily determined by spectroscopic analysis. The present study was aimed to evaluate the impact of biofield treatment on these properties of four pharmaceutical compounds such as urea, thiourea, sodium carbonate, and magnesium sulphate, using spectroscopic analysis. Each compound was divided into two groups, referred as control and treatment. The control groups remained as untreated and treatment group of each compound received Mr. Trivedi's biofield treatment. Control and treated samples of each compound were characterized using FourierTransform Infrared (FT-IR) and Ultraviolet-Visible (UV-Vis) spectroscopy. FT-IR spectra of biofield treated urea showed the shifting of $\mathrm{C}=\mathrm{O}$ stretching peak towards lower frequency $\left(1684 \rightarrow 1669 \mathrm{~cm}^{-1}\right)$ and $\mathrm{N}-\mathrm{H}$ stretching peak towards higher frequency $\left(3428 \rightarrow 3435 \mathrm{~cm}^{-1}\right)$ with respect to control. A shift in frequency of $\mathrm{C}-\mathrm{N}-\mathrm{H}$ bending peak was also observed in treated sample as compared to control i.e. $\left(1624 \rightarrow 1647 \mathrm{~cm}^{-1}\right)$. FT-IR spectra of thiourea showed upstream shifting of $\mathrm{NH}_{2}$ stretching peak $\left(3363 \rightarrow 3387 \mathrm{~cm}^{-1}\right.$ ) as compared to control, which may be due to decrease in $\mathrm{N}-\mathrm{H}$ bond length. Also, the change in frequency of N-C-S bending peak $\left(621 \rightarrow 660 \mathrm{~cm}^{-1}\right)$ was observed in treated thiourea that could be due to some changes in bond angle after biofield treatment. Similarly, treated sample of sodium carbonate showed decrease in frequency of $\mathrm{C}-\mathrm{O}$ bending peak $\left(701 \rightarrow 690 \mathrm{~cm}^{-1}\right)$ and magnesium sulphate showed increase in frequency of S-O bending peak $\left(621 \rightarrow 647 \mathrm{~cm}^{-1}\right)$ as compared to control, which indicated that bond angle might be altered after biofield treatment on respective samples. UV-Vis spectra of biofield treated urea showed shift in lambda $\max \left(\lambda_{\max }\right)$ towards higher wavelength $(201 \rightarrow 220 \mathrm{~nm})$ as compared to control sample, whereas other compounds i.e. thiourea, sodium carbonate, and magnesium sulphate showed the similar $\lambda_{\max }$ to their respective control. These findings conclude that biofield treatment has significant impact on spectral properties of tested pharmaceutical compounds which might be due to some changes happening at atomic level of compounds, and leading to affect the bonding and structural properties of compounds.
\end{abstract}

Keywords: Urea; Thiourea; Sodium carbonate; Magnesium sulphate; Biofield treatment; Fourier transform infrared spectroscopy; Ultraviolet-visible spectroscopy

\section{Introduction}

Pharmaceutical industries are an important component of health care systems which are largely driven by scientific discovery and development of various chemical and biological agents for human and animal health. The pharmaceutical industry is based primarily upon many organic and inorganic chemicals, which are used as raw materials, serve as reactants, reagents, catalysts, counter ions and solvents. However these chemicals exhibit a wide range of pharmacological activity and toxicological properties [1]. Although the pharma industries are dominated by organic compounds and drugs, the inorganic compounds also focus their attention due to their therapeutic potential such as neurological, anticancer, antimicrobial, antiulcer, antiviral, anti-inflammatory, cardio vascular and insulinmimetic agents. Moreover, inorganic compounds also play an important role as counter ions in drugs, which influence the solubility, stability, and hygroscopicity of active pharmaceutical ingredients [2]. The compounds selected in this study for biofield treatment are urea, thiourea, sodium carbonate and magnesium sulphate, which have wide applications in pharmaceutical industry.

Urea, a white crystalline powder is commonly used in denaturing and solubilising proteins in the biopharmaceutical industry. It serves an important role in the metabolism of nitrogen-containing compounds by animals and is the main nitrogen-containing substance in the urine of mammals. It is small hydrophilic molecule, present in all taxa, and widely used as protein denaturant in in vitro unfolding/ refolding experiments [3]. It is also used clinically as emollient and keratolytic agent in treatment of skin related diseases [4].

Thiourea is an organosulfur compound which is utilized in organic synthesis of various compounds and pharmaceuticals like sulfathiazoles, thiouracils, tetramizole and cephalosporins. Moreover, it was also used as thyroid depressant during 1940s [5,6].

Sodium carbonate, commonly known as washing soda, is sodium salt of carbonic acid. Naturally it exists in the form of crystalline heptahydrate; however it readily effloresces to form a white powder which is monohydrate [7]. Sodium carbonate $\left(\mathrm{Na}_{2} \mathrm{CO}_{3}\right)$ is a food additive and used as carbonating agent, anti-caking agent, raising agent, and stabilizer. Its activities are also reported as an alkalizing agent, used in lotion or bath in the treatment of scaly skin in pharmaceuticals [8].

Magnesium sulphate is commonly known as Epsom salt, and used both externally and internally in pharmaceutical preparation. In addition, Epsom salt is also used as bath salts and for isolation tanks. Oral

*Corresponding author: Snehasis Jana, Trivedi Science Research Laboratory Pvt. Ltd., Hall-A, Chinar Mega Mall, Chinar Fortune City, Hoshangabad Rd. Bhopal- 462026, Madhya Pradesh, India, Tel: +91-755-666-0006; E-mail: publication@trivedisrl.com

Received July 07, 2015; Accepted July 30, 2015; Published August 04, 2015

Citation: Trivedi MK, Patil S, Shettigar H, Singh R, Jana S (2015) An Impact of Biofield Treatment on Spectroscopic Characterization of Pharmaceutical Compounds. Mod Chem appl 3: 159. doi:10.4172/2329-6798.1000159

Copyright: ( $) 2015$ Trivedi MK, et al. This is an open-access article distributed under the terms of the Creative Commons Attribution License, which permits unrestricted use, distribution, and reproduction in any medium, provided the original author and source are credited. 
magnesium sulphate is commonly used as a saline laxative or osmotic purgative. Magnesium sulphate is the main compound for preparation of intravenous magnesium $[9,10]$. In all these four compounds, stability plays a crucial role in pharmaceutical preparations, which is directly related to its structural and atomic bonding properties. Currently, in pharmaceutical industries stability of these compounds is modulating through altering temperature and $\mathrm{pH}$ conditions [11]. Thus, it is important to evaluate an alternate strategy, which could alter the structural and bonding properties and that can affect the stability in these compounds.

Biofield is the scientific term for the biologically produced ultrafine electromagnetic energy field that can function for regulation and communication within the organism [12]. It is already demonstrated that electrical current exists inside the human body in the form of vibratory energy particles like ions, protons, and electrons and they generate magnetic field in the human body [13,14]. This electromagnetic field of the human body is known as biofield and energy associated with this field is known as biofield energy $[15,16]$. Thus, a human has the ability to harness the energy from environment or universe and can transmit the energy into any living or non-living object around this Globe. The object(s) always receive the energy and respond into useful way via biofield energy. This process is termed as biofield treatment. Mr Trivedi's biofield treatment (The Trivedi Effect ${ }^{\circledR}$ ) is recognized as an alternate approach to alter the several physical and structural properties of metal powder at atomic level [17-21]. The biofield treatment has also transformed the characteristics in several other fields like biotechnology [22,23], microbiology [24,25], and in agricultural science $[26,27]$.

IR spectroscopy which deals with the infrared region and UVVis spectroscopy which deals with ultraviolet-visible spectral region of the electromagnetic spectrum are used in analytical chemistry for the quantitative determination of different analytes, such as transition metal ions, highly conjugated organic compounds, and biological macromolecules [28]. They can provide analytically useful information on a large variety of compounds, ranging from small inorganic ions to large organic molecules [29]. Recently, effect of biofield treatment on ceramic oxide nano powders was studied using infrared spectroscopy, which reported that structural and bond properties were altered after treatment [30-33]. Hence based on the outstanding results achieved on different materials and considering the pharmaceutical applications of these four compounds, the present study was undertaken to evaluate the impact of biofield treatment on the spectroscopic characteristics of urea, thiourea, sodium carbonate, and magnesium sulphate.

\section{Materials and Methods}

\section{Study design}

The samples of urea, thiourea, sodium carbonate and magnesium sulphate were procured from Sigma-Aldrich, MA, USA; and each compound was divided into two parts i.e. as control and treatment group. The control samples remained as untreated, and treatment samples were handed over in sealed pack to Mr. Trivedi for biofield treatment under laboratory condition. Mr. Trivedi provided this treatment through his energy transmission process to the treated groups without touching the samples. After that, the control and treated samples of each compound were analysed using Fourier Transform Infrared (FT-IR) spectroscopy and Ultraviolet-Visible (UV-Vis) spectroscopy. Infrared and UV-Vis spectroscopy are particularly useful techniques in identifying organic as well as inorganic structures [34].

\section{FT-IR spectroscopic characterization}

The samples were crushed into fine powder for analysis. The powdered sample was mixed in spectroscopic grade $\mathrm{KBr}$ (1:20) in an agate mortar and pressed into $3 \mathrm{~mm}$ thick pellets with a hydraulic press. FT-IR spectra were recorded on Shimadzu's Fourier transform infrared spectrometer (Japan) with frequency range of $4000-500 \mathrm{~cm}^{-1}$ at room temperature. The FT-IR spectroscopic analysis of urea, thiourea, sodium carbonate and magnesium sulphate (control and treated) were carried out to evaluate the impact of biofield treatment at atomic and molecular level like bond strength, stability, rigidity of structure etc. The FTIR spectroscopy applied to determine any change in structural and bonding properties due to its ability to characterize the functional group and fingerprint region of very small quantities of samples.

\section{UV-Vis spectroscopic analysis}

The UV-Vis spectral analysis was measured using Shimadzu UV2400 PC series spectrophotometer over a wavelength range of 200-400 $\mathrm{nm}$ with $1 \mathrm{~cm}$ quartz cell and a slit width of $2.0 \mathrm{~nm}$. This analysis was performed to evaluate the effect of biofield treatment on structural property of different pharmaceutical compounds such as urea, thiourea, sodium carbonate and magnesium sulphate. With UV-Vis spectroscopy it is also possible to investigate electron transfers between orbitals or bands of atoms, ions and molecules existing in the gaseous, liquid and solid phase.

\section{Results and Discussion}

\section{FT-IR spectroscopic analysis}

Infrared (IR) spectroscopy is based on the vibrations of the atoms in a molecule. When a molecule absorbs infrared radiation, its chemical bonds vibrate and can stretch, contract or bend [35]. FT-IR spectra of control and treated samples of urea are shown in Figure 1. IR spectra of control urea sample showed in plane and out of plane $\mathrm{N}-\mathrm{H}$ stretching at $3428 \mathrm{~cm}^{-1}$. Other peaks showed $\mathrm{C}=\mathrm{O}$ stretching at 1684

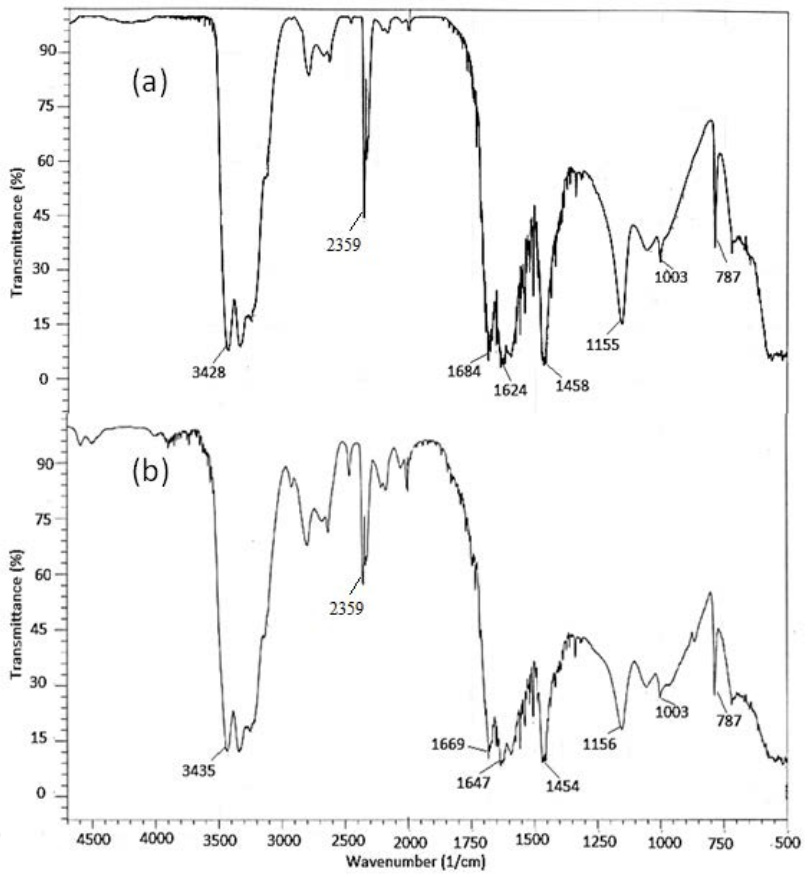

Figure 1: FT-IR spectra of urea. (a), control and (b), treated. 
$\mathrm{cm}^{-1}$; C-N-H bending at $1624 \mathrm{~cm}^{-1}$; C-N stretching at $1458 \mathrm{~cm}^{-1}$ and $1003 \mathrm{~cm}^{-1} ; \mathrm{NH}_{2}$ bending at $1155 \mathrm{~cm}^{-1}$ and out of plane $\mathrm{NH}_{2}$ bending at $787 \mathrm{~cm}^{-1}$. The spectrum was well supported by literature data [36]. The FT-IR spectrum of treated urea sample showed similar pattern of control IR absorption peaks except N-H stretching peak at $3435 \mathrm{~cm}^{-1}$, $\mathrm{C}=\mathrm{O}$ stretching peak at $1669 \mathrm{~cm}^{-1}$ and $\mathrm{C}-\mathrm{N}-\mathrm{H}$ bending peak at 1647 $\mathrm{cm}^{-1}$ (Table 1). The shifting of $\mathrm{C}=\mathrm{O}$ stretching peak towards lower frequency and $\mathrm{N}-\mathrm{H}$ stretching peak towards higher frequency were may be due to increase of conjugation effect in treated urea molecule. Due to conjugation, there may be increase in bond length of $\mathrm{C}=\mathrm{O}$ and decrease in bond length of N-H bond of urea. It is already reported that the peak frequency $(v)$ in IR spectra for any bond is directly proportional to its bond force constant $(\mathrm{k})$ [37]. Also the bond force constant $(\mathrm{k})$ is inversely related to average bond length (r) [38]. Hence, it is presumed that shifting of peak wavenumber corresponding to $\mathrm{C}=\mathrm{O}$ and $\mathrm{N}-\mathrm{H}$ bond could be due to change in corresponding bond length after biofield treatment. Data also exhibited that C-N-H bending frequency was shifted towards higher frequency as compared to control sample. It could be due to alteration in bond angle of $\mathrm{C}-\mathrm{N}-\mathrm{H}$ in urea after biofield treatment [39]. As there is occurrence of conjugation effect in treated sample due to biofield treatment, which may lead to increase stability in treated urea as compared to control. Apart from these peaks, small, sharp absorption bands in the region from 4000$3000 \mathrm{~cm}^{-1}$ and $1800-1600 \mathrm{~cm}^{-1}$ were appeared due to vapour phase water and the predominant $\mathrm{CO}_{2}$ absorption band occurs as a doublet at $2359 \mathrm{~cm}^{-1}$ in both control and treated sample.

FTIR spectra of control and treated samples of thiourea are shown in Figure 2. The FT-IR spectrum of control thiourea sample showed $\mathrm{NH}_{2}$ asymmetric and symmetric stretching peaks at $3363 \mathrm{~cm}^{-1}$ and 3169 $\mathrm{cm}^{-1}$ respectively. Other peaks were observed for C-N stretching at $1465 \mathrm{~cm}^{-1} ; \mathrm{C}=\mathrm{S}$ asymmetric and symmetric stretching at $1412 \mathrm{~cm}^{-1}$ and $730 \mathrm{~cm}^{-1}$ respectively; $\mathrm{C}-\mathrm{N}$ symmetric stretching peak at $1086 \mathrm{~cm}^{-1}$ and $\mathrm{N}-\mathrm{C}-\mathrm{S}$ bending at $621 \mathrm{~cm}^{-1}$. The peaks in spectrum of control sample were well supported by literature data $[40,41]$. The FT-IR spectrum of treated thiourea sample showed similar peaks like in control sample except $\mathrm{N}-\mathrm{C}-\mathrm{S}$ bending peak at $660 \mathrm{~cm}^{-1}$ and $\mathrm{NH}_{2}$ asymmetric stretching peak at $3387 \mathrm{~cm}^{-1}$ (Table 1). Hence, the shifting of $\mathrm{NH}_{2}$ stretching peak towards higher frequency as compared to control $\left(3363 \mathrm{~cm}^{-1} \rightarrow 3387\right.$ $\mathrm{cm}^{-1}$ ) suggest that biofield treatment may reduce the bond length. As described earlier, it ultimately may cause some changes in bond force constant i.e. strengthening of bond which could provide more stability to the compound. Also the change in frequency of N-C-S bending peak suggests that there may be some alteration in bond angle of treated sample as compared to control after biofield treatment. The FT-IR spectra also showed small, sharp absorption bands in the region from $4000-3000 \mathrm{~cm}^{-1}$ and $1800-1600 \mathrm{~cm}^{-1}$ which were appeared due to vapour phase water and a doublet peak at $2359 \mathrm{~cm}^{-1}$ due to $\mathrm{CO}_{2}$ absorption band in both control and treated sample.

The FT-IR spectra of control and treated samples of sodium carbonate are shown in Figure 3. The FT-IR spectrum of control sample was interpreted regarding the characteristic of IR absorption bands known for carbonate group [42]. IR spectrum of control sodium carbonate showed $\mathrm{C}-\mathrm{O}$ in plane and out of plane bending peaks at $881 \mathrm{~cm}^{-1}$ and $701 \mathrm{~cm}^{-1}$ respectively and C-O stretching peak at 1445 $\mathrm{cm}^{-1}$. The FT-IR spectrum of control sample also showed the peak at $2943 \mathrm{~cm}^{-1}$ i.e. O-H stretching frequency which could be due to water absorption by sample. The vapour phase water absorption is also evident due to appearance of small, sharp peaks in region of 4000-3000 $\mathrm{cm}^{-1}$. The treated sample also showed $\mathrm{O}-\mathrm{H}$ stretching peak at 3007 $\mathrm{cm}^{-1}$ other than small and sharp peaks in region of $4000-3000 \mathrm{~cm}^{-1}$ due to water absorption. The spectrum of treated sample showed similar peaks except C-O out of plane bending peak i.e. at $690 \mathrm{~cm}^{-1}$ [43]. The change in $\mathrm{C}-\mathrm{O}$ bending peak as compared to control sample (Table 2) could be possible due to some change in bond angle of treated sample after biofield treatment.

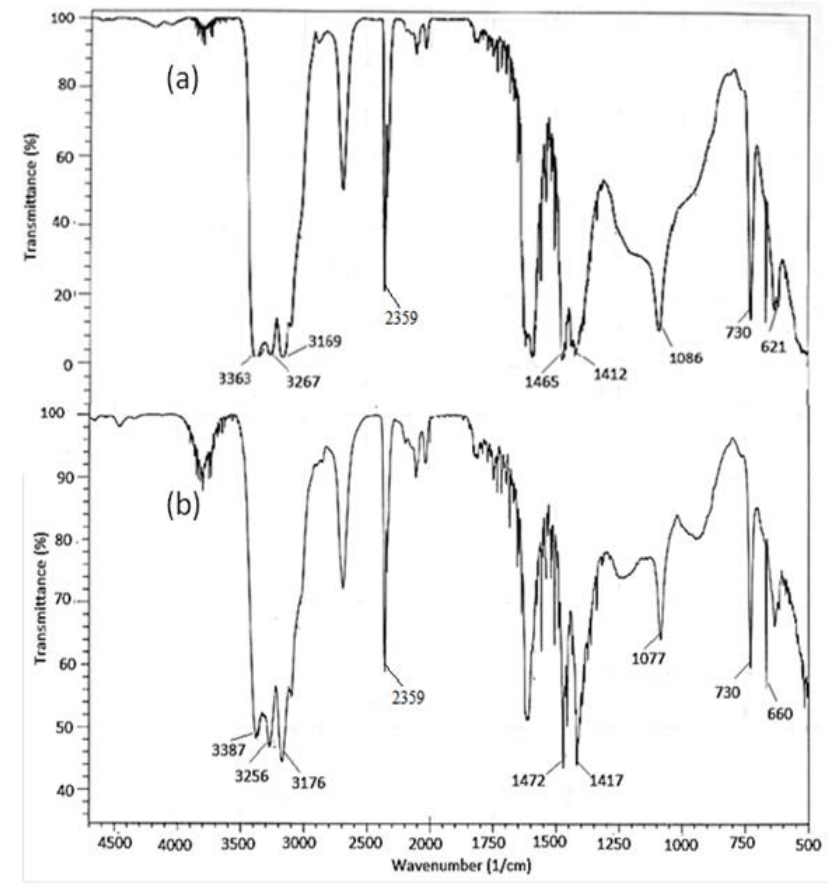

Figure 2: FT-IR spectra of thiourea. (a), control and (b), treated.

\begin{tabular}{|c|c|c|c|c|c|}
\hline \multirow{3}{*}{ S. No. } & \multirow{3}{*}{ Functional group } & \multicolumn{4}{|c|}{ Wavenumber $\left(\mathrm{cm}^{-1}\right)$} \\
\hline & & \multicolumn{2}{|c|}{ Urea } & \multicolumn{2}{|c|}{ Thiourea } \\
\hline & & Control & Treatment & Control & Treatment \\
\hline 1. & $\mathrm{~N}-\mathrm{H}$ stretching (in plane) & 3428 & 3435 & 3169 & 3176 \\
\hline 2. & $\mathrm{~N}-\mathrm{H}$ stretching (out of plane) & - & - & 3363 & 3387 \\
\hline 3. & $\mathrm{C}=\mathrm{O}$ stretching & 1684 & 1669 & - & - \\
\hline 4. & $\mathrm{C}-\mathrm{N}-\mathrm{H}$ bending & 1624 & 1647 & - & - \\
\hline 5. & C-N stretching & 1458,1003 & 1454,1003 & 1465,1086 & 1472,1077 \\
\hline 6. & $\mathrm{NH}_{2}$ bending (in plane) & 1155 & 1156 & - & - \\
\hline 7. & $\mathrm{NH}_{2}$ bending (out of plane) & 787 & 787 & - & - \\
\hline 8. & $\mathrm{C}=\mathrm{S}$ asymmetric stretching & - & - & 1412 & 1417 \\
\hline 9. & $\mathrm{C}=\mathrm{S}$ symmetric stretching & - & - & 730 & 730 \\
\hline 10. & N-C-S bending & - & - & 621 & 660 \\
\hline
\end{tabular}

Table 1: Vibration modes observed in organic pharmaceutical compounds such as urea and thiourea. 
Citation: Trivedi MK, Patil S, Shettigar H, Singh R, Jana S (2015) An Impact of Biofield Treatment on Spectroscopic Characterization of Pharmaceutical Compounds. Mod Chem appl 3: 159. doi:10.4172/2329-6798.1000159

Page 4 of 6

FT- IR spectra of control and treated magnesium sulphate samples are shown in Figure 4. The spectrum of control sample showed $\mathrm{O}-\mathrm{H}$ stretching peak at $3355 \mathrm{~cm}^{-1}$ and $\mathrm{O}-\mathrm{H}$ bending peak at $1684 \mathrm{~cm}^{-1}$ which may be appeared due to absorption of water molecules by compound. IR spectra of treated sample also showed $\mathrm{O}-\mathrm{H}$ stretching and bending peaks at $3279 \mathrm{~cm}^{-1}$ and $1660 \mathrm{~cm}^{-1}$ respectively. The absorption of vapour phase water is also evident by appearance of small peaks in region of $4000-3000 \mathrm{~cm}^{-1}$ and $1800-1600 \mathrm{~cm}^{-1}$ in both control and treated sample. Also a predominant $\mathrm{CO}_{2}$ absorption band occurs as a doublet at $2359 \mathrm{~cm}^{-1}$ in both control and treated sample. Other peaks appeared in control sample were mainly due to presence of sulphate group. These were S-O asymmetric stretching peak at $1070 \mathrm{~cm}^{-1}$; S-O symmetric stretching at $983 \mathrm{~cm}^{-1}$ and S-O bending at $621 \mathrm{~cm}^{-1}[44,45]$. In case of treated sample spectra, similar peaks were observed. The only change observed was in S-O bending peak, which was shifted to higher frequency as compared to control sample $\left(621 \rightarrow 647 \mathrm{~cm}^{-1}\right)$ (Table 2). It may be due to alteration in bond angle S-O after biofield treatment.

\section{UV-Vis spectroscopic analysis}

The $\lambda_{\max }$ value corresponding to each control and treated samples are shown in Table 3. In UV spectra of control urea sample, the absorption peak was shown at $201 \mathrm{~nm}$ whereas in treated sample the

\begin{tabular}{|c|c|c|c|c|c|}
\hline \multirow{3}{*}{ S. No. } & \multirow{3}{*}{ Functional group } & \multicolumn{4}{|c|}{ Wavenumber $\left(\mathrm{cm}^{-1}\right)$} \\
\hline & & \multicolumn{2}{|c|}{ Sodium carbonate } & \multicolumn{2}{|c|}{ Magnesium sulphate } \\
\hline & & Control & Treatment & Control & Treatment \\
\hline 1. & $\mathrm{O}-\mathrm{H}$ stretching & 2943 & 3007 & 3355 & 3279 \\
\hline 2. & C-O stretching & 1445 & 1440 & - & - \\
\hline 3. & $\mathrm{C}-\mathrm{O}$ bending (in plane) & 881 & 881 & - & - \\
\hline 4. & C-O bending (out of plane) & 701 & 690 & - & - \\
\hline 5. & $\mathrm{O}-\mathrm{H}$ bending & 1772 & 1772 & 1684 & 1660 \\
\hline 6. & S-O asymmetric stretching & - & - & 1070 & 1077 \\
\hline 7. & S-O symmetric stretching & - & - & 983 & 985 \\
\hline 8. & S-O bending & - & - & 621 & 647 \\
\hline
\end{tabular}

Table 2: Vibration modes observed in inorganic pharmaceutical compounds such as sodium carbonate and magnesium sulphate.

\begin{tabular}{|c|c|c|c|}
\hline \multirow{2}{*}{ S. No. } & Name of compound & \multicolumn{2}{|c|}{ Lambda max (nm) } \\
\cline { 2 - 3 } & Urea & 201 & 20 \\
\hline 1. & Thiourea & 241,202 & 206 \\
\hline 3. & Sodium carbonate & 202 \\
\hline 4. & Magnesium sulphate & 358 \\
\hline
\end{tabular}

Table 3: Maximum absorbance wavelength of control and treated sample of different pharmaceutical compounds.

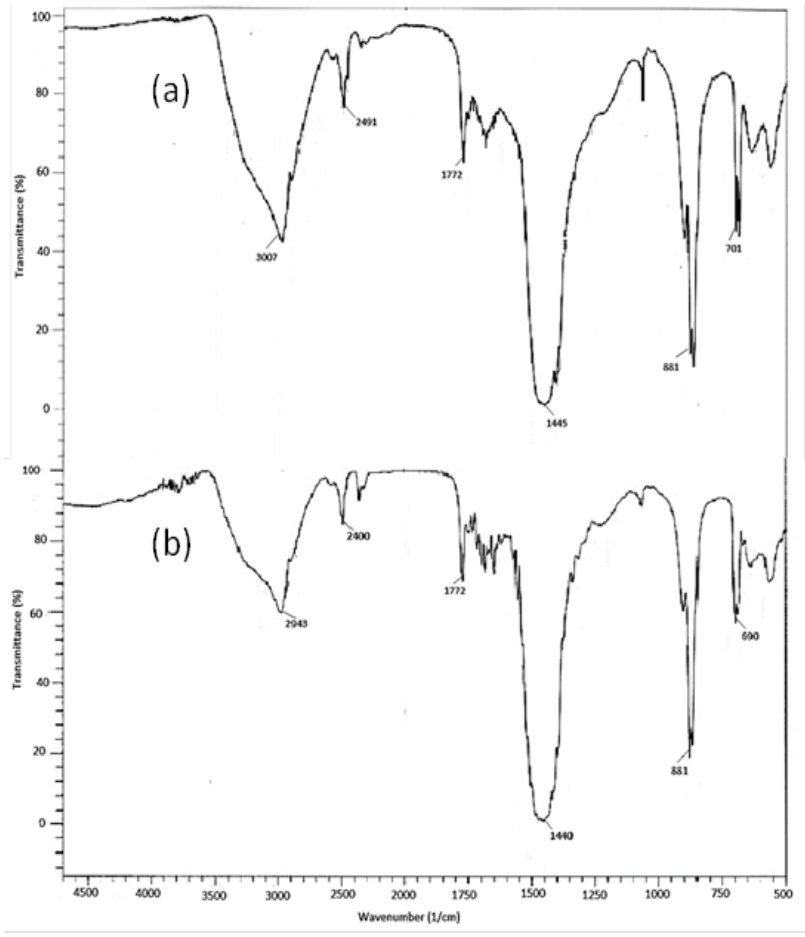

Figure 3: FT-IR spectra of sodium carbonate. (a), control and (b), treated

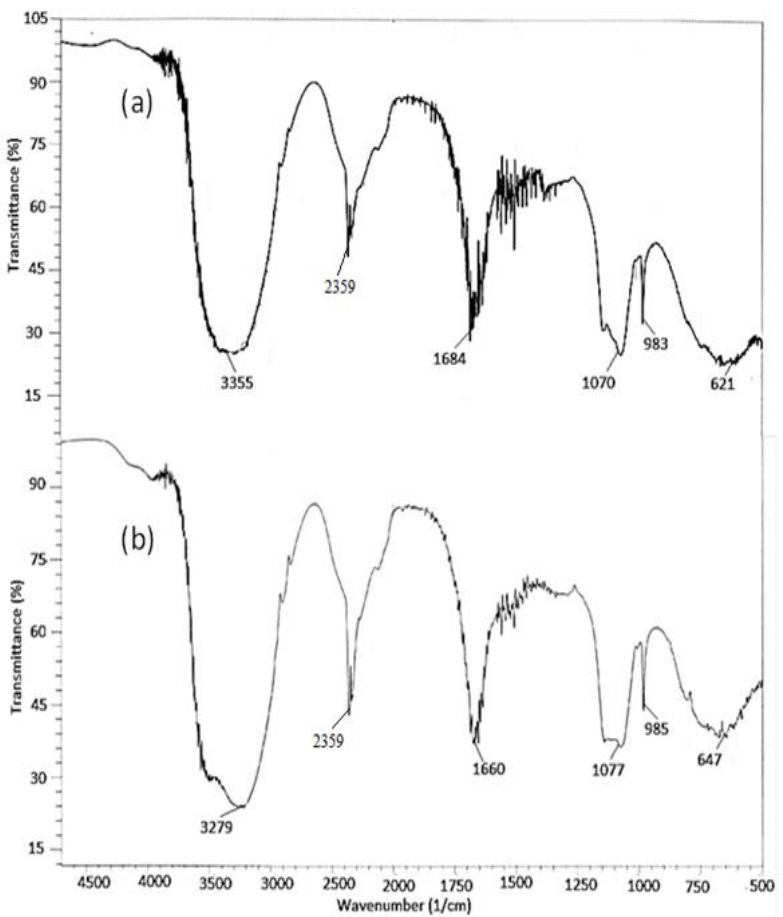

Figure 4: FT-IR spectra of magnesium sulphate. (a), control and (b) treated. 
absorption peak was appeared at $220 \mathrm{~nm}$. Shifting of $\lambda_{\max }$ towards higher wavelength in treated sample as compared to control may occur due to increase in conjugation effect in urea molecule. This result was also supported by FT-IR data. Further, it is assumed that conjugation in treated urea may lead to higher stability after biofield treatment [46]. In UV spectra of both control and treated samples of thiourea showed two absorption peaks (202 and $241 \mathrm{~nm}$ ) and were well supported by literature data [38]. The UV spectra of control and treated samples of sodium carbonate also showed similar pattern of $\lambda_{\max }$ i.e. at $206 \mathrm{~nm}$ and which was well supported by literature data [47]. Similarly no change was found in $\lambda_{\max }$ in UV spectra of treated magnesium sulphate as compared to control. These observations suggest that biofield treatment might not make any alteration in chromophore groups present in thiourea, sodium carbonate and magnesium sulphate which are mainly responsible for absorption of light.

Our group previously reported the impact of biofield energy on physical, thermal and spectroscopic characteristics of various metals and powders [30-33]. The present study also showed the effect of biofield treatment on structural and bonding properties of different pharmaceutical compounds which are used in pharmaceutical industry because of their intrinsic pharmacological action or as intermediate agent. The change in IR frequencies and $\lambda_{\max }$ suggest that due to increase in conjugation effect or force constant between bonds (e.g., urea and thiourea), chemical stability of these compounds might increase after biofield treatment. The increase in stability can improve their shelf life and effectiveness [48] and make them more suitable to be used in pharmaceutical preparations.

\section{Conclusion}

Altogether, the results of present study showed that there has significant impact of biofield treatment on spectral properties of urea, thiourea, sodium carbonate, and magnesium sulphate. FT-IR data showed significant change in stretching frequencies in treated sample of urea which may be due to increased conjugation effect induced by biofield treatment and attribute to increased stability of treated urea sample. Similarly, a significant change was found in IR peak frequencies related to stretching and bending vibrations of treated samples of thiourea, sodium carbonate and magnesium sulphate which could be due to alteration in bond angle and bond strength after biofield treatment. UV spectroscopic result of urea was also supported by IR data, which suggest that biofield treatment may alter the conjugation effect within the molecule. Thus, it is postulated that biofield treatment can make some alteration at the atomic level, which could further affect the stability of the bonds and hence, the stability of compounds.

\section{Acknowledgement}

The authors would like to acknowledge the whole team of MGV Pharmacy College, Nashik for providing the instrumental facility.

The generous support of Trivedi Science, Trivedi Master Wellness and Trivedi Testimonials is gratefully acknowledged.

\section{References}

1. Stellman JM (1988) Encyclopedia of occupational health and safety. (4 $4^{\text {th }}$ edition) International Labor Organization, Geneva, Switzerland.

2. Sekhon BS, Gandhi L (2006) Medicinal uses of inorganic compounds-1. Resonance 11: 75-89.

3. Kurzer F, Sanderson PM (1956) Urea in the history of organic chemistry: Isolation from natural sources. J Chem Educ 9: 452-459.

4. Pan M, Heinecke G, Bernardo S, Tsui C, Levitt J (2013) Urea: a comprehensive review of the clinical literature. Dermatol Online J 19: 20392.

5. Schreiner PR1 (2003) Metal-free organocatalysis through explicit hydrogen bonding interactions. Chem Soc Rev 32: 289-296.

6. Angerer JK, Schaller KH (1988) Analyses of hazardous substances in biological materials. Fresenius' Journal of Analytical Chemistry 346: 828-829.

7. Pabst $A$ (1930) On the hydrates of sodium carbonate. Am Mineral 15: 69-73.

8. http://medical-dictionary.thefreedictionary.com/sodium+carbonate

9. Buchel $\mathrm{KH}$, Moretto $\mathrm{HH}$, Woditsch $\mathrm{P}(2000)$ Industrial inorganic chemistry $\left(2^{\text {nd }}\right.$ edition) Wiley-VCH, Germany.

10. Frakes MA, Richardson LE 2nd (1997) Magnesium sulfate therapy in certain emergency conditions. Am J Emerg Med 15: 182-187.

11. Panyachariwat N, Steckel $H$ (2014) Stability of urea in solution and pharmaceutical preparations. J Cosmet Sci 65: 187-195.

12. Garland SN, Valentine D, Desai K, Li S, Langer C, et al. (2013) Complementary and alternative medicine use and benefit finding among cancer patients. J Altern Complement Med 19: 876-881.

13. Planck M (1956) Treatise on thermodynamics, (3 ${ }^{\text {rd }}$ edition) Longmans, Green, London (UK).

14. Einstein A (1905) Does the inertia of a body depend upon its energy-content. Ann Phys 18: 639-641.

15. Rivera-Ruiz M, Cajavilca C, Varon J (2008) Einthoven's string galvanometer: the first electrocardiograph. Tex Heart Inst J 35: 174-178.

16. Rubik B (2002) The biofield hypothesis: its biophysical basis and role in medicine. J Altern Complement Med 8: 703-717.

17. Trivedi MK, Tallapragada RM (2008) A transcendental to changing metal powder characteristics. Met Powder Rep 63: 22-28.

18. Trivedi MK, Tallapragada RM (2009) Effect of super consciousness external energy on atomic, crystalline and powder characteristics of carbon allotrope powders. Mater Res Innov 13: 473-480.

19. Dabhade VV, Tallapragada RMR, Trivedi MK (2009) Effect of external energy on atomic, crystalline and powder characteristics of antimony and bismuth powders. Bull Mater Sci 32: 471-479.

20. Trivedi MK, Patil S, Tallapragada RM (2013) Effect of biofield treatment on the physical and thermal characteristics of vanadium pentoxide powder. J Material Sci Eng S11: 001.

21. Trivedi MK, Patil S, Tallapragada RM (2014) Atomic, crystalline and powder characteristics of treated zirconia and silica powders. J Material Sci Eng 3: 144

22. Patil S, Nayak GB, Barve SS, Tembe RP, Khan RR (2012) Impact of biofield treatment on growth and anatomical characteristics of Pogostemon cablin (Benth.). Biotechnology 11: 154-162.

23. Nayak G, Altekar N (2015) Effect of a biofield treatment on plant growth and adaptation. J Environ Health Sci 1: 1-9.

24. Trivedi MK, Patil S, Bhardwaj $Y$ (2008) Impact of an external energy on Staphylococcus epidermis [ATCC-13518] in relation to antibiotic susceptibility and biochemical reactions-An experimental study. J Accord Integr Med 4: 230235 .

25. Trivedi MK, Patil S, Bhardwaj $Y$ (2009) Impact of an external energy on Enterococcus faecalis [ATCC-51299] in relation to antibiotic susceptibility and biochemical reactions-An experimental study. J Accord Integr Med 5: 119-130.

26. Shinde V, Sances F, Patil S, Spence A (2012) Impact of biofield treatment on growth and yield of lettuce and tomato. Aust J Basic \& Appl Sci 6: 100-105.

27. Lenssen AW (2013) Biofield and fungicide seed treatment influences on soybean productivity, seed quality and weed community. Agricultural Journal 8: 138-143.

28. Misra P, Dubinskii M (2002) Ultraviolet spectroscopy and UV lasers. Marcel Dekker. New York, USA.

29. Ovalles F, Gallignani M, Rondon R, Brunetto MR, Luna R (2009) Determination of sulfate for measuring magnesium sulfate in pharmaceuticals by flow analysisFourier transforms infrared spectroscopy. Lat Am J Pharm 28: 173-182.

30. Trivedi MK, Nayak G, Patil S, Tallapragada RM, Latiyal O (2015) Studies of the atomic and crystalline characteristics of ceramic oxide nano powders after bio field treatment. Ind Eng Manage 4: 161.

31. Trivedi MK, Patil S, Tallapragada RM (2013) Effect of biofield treatment on the physica and thermal characteristics of silicon, tin and lead powders. J Material Sci Eng 2: 125. 
Citation: Trivedi MK, Patil S, Shettigar H, Singh R, Jana S (2015) An Impact of Biofield Treatment on Spectroscopic Characterization of Pharmaceutical Compounds. Mod Chem appl 3: 159. doi:10.4172/2329-6798.1000159

32. Trivedi MK, Patil S, Tallapragada RM (2012) Thought Intervention through bio field changing metal powder characteristics experiments on powder characterization at a PM plant. Proceeding of the 2 nd International Conference on Future Control and Automation 2: 247-252.

33. Trivedi MK, Patil S, Tallapragada RM (2015) Effect of biofield treatment on the physical and thermal characteristics of aluminium powders. Ind Eng Manage 4: 151

34. Sibilia JP (1996) A guide to materials characterization and chemical analysis. John Wiley and Sons Ltd, USA.

35. Barbara S (2004) Infrared Spectroscopy: Fundamentals and applications. Wiley-VCH, Germany.

36. Piasek Z, Urbanski T (1962) The infra-red absorption spectrum and structure of urea. B Pol Acad Sci-Tech X: 113-120.

37. Ghosh M, Dilawar N, Bandyopadhyay AK, Raychaudhuri AK (2009) Phonon dynamics of $\mathrm{Zn}(\mathrm{Mg}, \mathrm{Cd}) \mathrm{O}$ alloy nanostructures and their phase segregation. J Appl Phys 106: 1-6.

38. EL-Mallawany RA (1989) Theoretical and experimental IR spectra of binary rare earth tellurite glasses-1. Infrared Phys 29: 781-785.

39. Pretsch E, Buhlmann P, Affolter C (2009) Structure Determination of Organic Compounds. ( $4^{\text {th }}$ edition). Springer Verlag, Berlin, Heidelberg, Germany.

40. Ravi B, Jegatheesan A, Neelakandaprasad B, Sadeeshkumar C, Rajarajan G
(2014) Optical and conductivity analysis of thiourea single crystals. Rasayan J Chem 7: 287-294.

41. Begum SA, Hossain M, Podder J (2009) An investigation on the growth and characterization of thiourea single crystal grown from aqueous solutions. J Bangladesh Acad Sci 33: 63-70.

42. Miller FA, Wilkins $\mathrm{CH}$ (1952) Infrared spectra and characteristic frequencies of inorganic ions. Anal Chem 24: 1253-1294.

43. Coates J (2000) Interpretation of infrared spectra, a practical approach Encyclopedia of Analytical Chemistry. John Wiley and Sons Ltd, USA

44. Chaban GM, Huo WM, Lee TJ (2002) Theoretical study of infrared and raman spectra of hydrated magnesium sulfate salts. J Chem Phys 117: 2532-2537.

45. Sieranski T, Kruszynski R (2012) Magnesium sulfate complexes with hexamethylenetetramine and 1, 10-phenanthroline: Thermal, structural and spectroscopic properties. J Therm Anal Calorim 109: 141-152.

46. Filutowicz Z, Lukaszewski K, Pieszynski K (2004) Remarks on spectraphotometric monitoring of urea in dialysate. JMIT 8: 105-110.

47. Adams GE, Boag JW, Michael BD (1965) Reactions of the hydroxyl radical Part 1.-Transient spectra of some inorganic radical-anions. Trans Faraday Soc 61: $1674-1680$.

48. Blessy M, Patel RD, Prajapati PN, Agrawal YK (2014) Development of forced degradation and stability indicating studies of drugs-A review. J Pharm Anal 4: 159-165. 